\title{
Sustainability communication and its effect in consumer intention to visit a tourist destination
}

\section{Comunicação de sustentabilidade e seu efeito na intenção do consumidor para visitar um destino turístico}

\author{
Francisco Vicente Sales Melo \\ Universidade Federal de Pernambuco, Departamento de Ciências Administrativas, Recife, PE, Brasil, vicsmelo@gmail.com
}

Salomão Alencar de Farias

Universidade Federal de Pernambuco, Departamento de Ciências Administrativas, Recife, PE, Brasil, saf@ufpe.br

\begin{abstract}
This article investigated if the rational and hedonic of sustainability stimuli inserted in communications of touristic leisure destinations, moderated by emotions, involvement and ecological awareness are related to the consumer intention to visit a tourist destination. The research was made through an experimental design with manipulation between groups. Text messages manipulated the sustainability stimuli, and presented only one manipulated condition to each participant. It was found that the hedonic sustainability stimuli have a stronger effect over the consumer's intention, especially to those with low ecological awareness. The study contributes to literature by revealing that despite the emotion constructs and the fact that ecological involvement and awareness are not strong moderators in the relation between rational or hedonic sustainability stimuli and intention, they are aspects that, when positively activated, especially from hedonic arguments of sustainability, generate greater intention to visit destination by the consumer.
\end{abstract}

Keywords: Rational/hedonic communication, emotion, involvement, ecological awareness, sustainability in tourism.

\section{Resumo}

Este artigo buscou identificar se os estímulos racionais e hedônicos de sustentabilidade inseridos em comunicações de destinos turísticos de lazer, moderados pelas emoções, envolvimento e consciência ecológica, se relacionam com a intenção de visitar um destino turístico por parte do consumidor. A pesquisa adotou um desenho experimental com manipulação entre grupos. Os estímulos de sustentabilidade foram manipulados por meio de mensagens textuais, sendo que cada participante foi apresentado a apenas uma condição manipulada. Encontrou-se que o estímulo hedônico de sustentabilidade tem maior efeito sobre a intenção do consumidor, sobretudo para aqueles com baixa consciência ecológica. O estudo contribui para a literatura ao revelar que apesar dos construtos emoção, envolvimento e consciência ecológica não serem fortes moderadores na relação entre estímulos racionais ou hedônicos de sustentabilidade e a intenção, são aspectos que, quando ativados positivamente, especialmente a partir dos argumentos hedônicos de sustentabilidade, geram maior intenção de visitar o local por parte do consumidor.

Palavras-chave: Comunicação racional/hedônica, emoção, envolvimento, consciência ecológica, sustentabilidade no turismo.

\section{Introduction}

The relation between leisure tourism and sustainability is complex and received considerable attention from researchers and those interested in the subject. The aim is to find means to direct conservation practices of the places, both by strategic actions to maintain and ensure the economical aspect of the activity (Andrades-Caldito, Sanchez-Rivero \& Pulido-Fernandez, 2014) and by the creation of positive experiences towards preservation that may be lived by consumers during visitation (Miller, Merrilees \& Coghlan, 2014; Walker \& Moscardo, 2014). Although the possibility exists, some destinations seem not to balance the exploitation of attractions with sustainability.

The point is that the actions of sustainability currently performed by some destinations are generally not very effective and hardly involve the consumers in the process of preservation. In addition, even when they are performed, they are generally not disclosed in marketing communications related to the destination. Thereby, if the strategy is to maintain destination in a sustainable way and communicate the actions rationally necessary for it, it is believed that it is necessary to understand better how to activate the consumers' emotions for sustainability and involve them with that issue in the beginning of the process of choosing a place for the leisure travel. Especially when the aim is also to increase their intention to travel and awaken their interest to develop practical actions of sustainability from the choice. In other words, when consumers search for information about the place by means of advertising.

Advertising may be predominantly rational or emotional, and the decision about which appeal is more effective for the goal one wants to achieve, in terms of positive consumer response, is critical for managers (Samuelsen \& Olse, 2010). Based on this, it is believed that in order to disclose a tourist destination, those responsible for the destinations may use different types of communications, which can be structured in rational or emotional manners. From the need to adjust to the market trends concerning green or ecological marketing (Schmidt \& Donsbach, 2012; Matthes, Wonneberger \& Schmuck, 2014), especially when the company embraces sustainability practices and has the desire to inform their market, the use of appeals related to sustainability can also be contemplated.

Hartmann, Ibáñez \& Sainz (2005), indicate that there are three ways to accomplish communication with green appeal: functional, emotional or by combining both. However, it was found that the manner in which appeals are presented by authors are related to the characteristics presented in communication, where rational are the functional information, emotional are the images, and the combination is the use of 
both of them. Furthermore, although they concluded that the three types of advertising exercise significant impact over the evaluation of a brand, those effects were not tested independently. Petty and Cacioppo (1990) already considered that effectiveness of a rational or emotional appeal depends on the consumer's involvement, something not contemplated in Hartmann, Ibáñez and Sainz (2005) study. Recently, Matthes, Wonneberger \& Schmuck (2014) studied the green appeals and contemplated the involvement in the relation between the types of green advertising and the attitude of the brand. However, involvement was treated with an environmental focus, contemplating three other concepts such as environmental concern, green attitude and green purchase behavior. Although environmental awareness has been contemplated, it is believed that those variations could have been analyzed separately. Roberts (1996) considers that in analysis related to environmental (or sustainability) issues, ecological awareness, intrinsically related to the individual's behavior, must be analyzed independently in order to observe its influence in the behavior.

Although the previously commented constructs have been used in the study by Matthes, Wonneberger \& Schmuck (2014), the advertising model is not independent and the evaluation of the communication on the consumer's behalf is executed based on the variations between the visual and textual scenario, not only the stimulus related to the green aspect is highlighted. It was also observed that the analyzed researches do not contemplate emotion as a moderator of the relation between sustainability (or green) rational and emotional communication and the attitude of the brand or behavioral intention. However, as tourism is a service of experimental nature and tends to arouse consumer's emotions (Hirschman \& Holbrook, 1982) it is considered that this construct may influence the relation between the types of sustainability advertising and behavioral intention.

In revised literature, it was not seen any discussions over which kind of tourism communication (rational or hedonic) would be more effective when the proposal is to stimulate the consumer by the sustainability of the place and inform the need of preservation practices during visitation. Although there are indications that some consumers prefer to travel to sustainable places, it was also not located any study that indicated the preference manifested in the process of choice. Furthermore, tourism already presents by itself an emotional scenario and the sustainability issue tends to be a necessity of rational nature. With that, it is believed that textual arguments should be more evident to suppress that possible scenario incompatibility, not only considering that the rational appeal would be the functional aspects and the emotional would be the images related to the analyzed context, as Hartmann, Ibáñez \& Sainz (2005) suggests.

In this sense, this study attempts to fill those gaps of identified researches, aiming to verify if the rational and hedonic sustainability stimuli inserted in communications of touristic leisure destinations, moderated by emotions, involvement and ecological awareness, relate themselves with the intention to visit a tourist destination on the consumer's behalf; effect that so far have not been investigated taking tourism as context.

\section{Rational and hedonic communication with and without sustainability appeal}

Marketing literature has been suggesting that a positioning towards sustainability, also known as a green positioning, is an essential factor for organizations in present and future days. Green has awakened a concern on people worldwide. On the other hand, although nowadays it is more common on corporate practices, there are still a few studies that analyze the processing of such messages, as well as their effectiveness in the consumers' evaluation (Hartmann, Ibáñez \& Sainz, 2005; Matthes, Wonneberger \& Schmuck, 2014). Transmitting sustainability implies in active disclosure of attributes related to the sustainability practices embraced by a company.

Aaker (1996) considers that the attributes of a brand may be structured based on functional (rational) and emotional (hedonic) attributes. Thereby, if considered the context of a tourist destination, for a rational positioning, the management of the place should establish strategies that could be able to transmit their sustainability practices, as well as the importance of executing them during the visitation. The practices may include, for example, paying preservation fees, obedience to norms and restricted access, paying fines, participating in training to access a preservation site, specific garments, standard conduct, care of the waste generated, among other things. This becomes relevant, seeing that some studies confirmed environmental and sustainability arguments influence the consumer's intention of choice and purchase (Roberts, 1996; Hartmann \& Apaolaza-Ibáñez, 2009).

Other studies indicate that brand publicity with emotional appeal, unlike the rational, might only transfer responses of affective nature towards the brand (Edell \& Burke, 1987). However, Searles (2010) affirms that information regarding environment protection, when presented enthusiastically and reinforced by verbal signs from an individual in a political context, influence the pro-environment attitude. Yet, when the appeals cause anxiety, they induce antienvironmental attitudes. His study also demonstrates that positive emotions influence environment attitudes more significantly. Lwin et al. (2014) verified which type of appeal (rational or emotional) is more effective when inserted in publicity of hospitality services on websites. Results indicated that the websites with emotional appeal create a more positive relation with the consumer's attitude and intention of purchase. They also indicated that emotional appeals are better to keep the consumer's interest and attention.

On the other hand, it was verified that rational matters endorse the decisions and choices of the consumers (Fishbein \& Ajzen, 1975; Ajzen, Albarracín \& Hornik, 2007). Accordingly, it is assumed that a sustainable practice would be something rational, since it requires a concern with the preservation and 
future of the place. Therefore, the rational sustainability stimuli would be more suitable to influence positively the consumer's behavioral intention (for example, necessity of preservation of the place). However, in a situation of touristic consumption in which the consumer tends to live hedonic experiences from the beginning of the process of information search and destination choice (Allen, 2000; Mossberg, 2008; Xu, 2010), it is speculated that hedonism would tend to be more predominant. Textual influence is believed to be more relevant in the consumer's evaluation. Thereby, it was tested whether hedonic textual sustainability stimuli inserted in the communication of a tourist destination would be more effective. Facing that dichotomy, hitherto not tested empirically, the following hypothesis is formulated: H1: Hedonic sustainability stimulus inserted in the communication of a tourist destination creates a more positive behavioral intention by the tourism consumer.

\section{Consumer emotions in tourism}

Tourist activity is loaded with practices that relate to the emotional responses from the individuals (for example, visiting attractions, know the cuisine, culture, among others) (Mossberg, 2008; Xu, 2010) which tends to be different from a regular sustainability practice, since it requires a rational behavior. The affirmative is valid, for it was verified that consumption through emotions is related to the intrinsic pleasure and not to the way to solve any problems in the physical environment, this being the basis for the understanding of hedonism, which refers to sensorial pleasure. In hedonic consumption, according to Hirschman \& Holbrook (1982), the goods and services are used to pleasure us through the senses, in order to help create fantasies that provide emotional stimuli.

Malone, McCabe \& Smith (2014) investigated the role of hedonism in the ethical processes of choice on the tourists' behalf. The authors analyzed how hedonism could establish connections between the hedonic experiences and the intentions towards future ethical behavior of the tourists. The results indicated that the experiences emotionally loaded are powerful motivators of ethical choice from the consumers. The study highlights the role hedonism plays in the process of streamlining and reinforcing the current and the intended ethical behavior, besides being a relevant moderator in relation to intention. To Gilmore \& Pine II (2002) when an individual purchases a service, they acquire a set of intangible activities performed on their behalf. When they purchase an experience, the consumer pays to spend a determinate amount of time enjoying a series of memorable events, made to involve them in theatrical form, something common in tourism.

On that subject, Mossberg (2008) considers that one of the previous conditions for the consumer to immerse in an extraordinary experience in the tourist destination is the preparation of the place with a hedonic scenery in a way that it could activate the emotions from several stimuli. The experience occurs when the companies, here the destinations, are capable to arouse the positive emotions and involve their clients to use the services as stages and the goods as accessories
(Gilmore \& Pine II, 2002; Mossberg, 2008; Brunner-Sperdin \& Peters, 2009). Considering the tourist context, it is assumed that if the consumers' emotional response is more positive towards a hedonic sustainability stimulus, their behavioral intention will be greater. Thereby, the following hypothesis was formulated: H2: A hedonic sustainability stimulus inserted in the communication of a tourist destination has a greater positive impact in the behavioral intention when the emotional response of the consumer towards the stimulus is more positive. The next section presents some theoretical considerations about consumer involvement.

\subsection{Consumer involvement}

For being important moderator, consumer involvement has been one of the central issues in the study of consumer behavior, since it can fundamentally influence the evaluation processes regarding certain objects and intention response (Clarke \& Belk, 1978). Theorists began to see that behavior in two directions: with low and high participation (Clarke \& Belk, 1978). Lastovicka \& Gadner (1978) demonstrated that the same product could have different levels of involvement between different people. In the same line of thought, Clark \& Belk (1978) evidenced that different purchasing situations for the same products cause difference in the research (search for information) and evaluation. That means the participation level may develop in the moment of consumption or experience, making it possible to work the differences among people, objects and situations.

Studies in the field of consumer behavior began to include the involvement construct in multiple contexts. These usually related the concept to products (Zaichkowsky, 1985; Laurent \& Kapferer, 1985; Michaelidou \& Dibb, 2006), the purchase decision, task, activity or event (Mittal \& Lee, 1989), to a publicity or processing of a message (Andrews, et al., 1990), as well as services in general (Zaichowsky, 1994) and touristic services (Gross \& Brown, 2008; Sigala, 2014). In recent survey on sustainability, Sigala (2014) proposes a framework to understand the role of the consumer in the sustainable management in the whole supply chain of tourism and hospitality. It presents a conceptual frame that identifies and synthesizes the several parts and impacts of the consumers' involvement in the implantation of a management model of the sustainability supply chain in tourism. Although the model proposed by Sigala (2014) presents a complex relation between the dimensions, which makes its validation difficult, the idea contributes to the development of the studies that aim to establish better understanding of the several manners in which consumers can contribute to the sustainability supply chain of tourism, from their involvement.

By analyzing some studies (Gilmore \& Pine II, 2002; Mossberg, 2008; Brunner-Sperdin \& Peters, 2009), it is also possible to theorize that if the stimuli towards sustainability practices are elaborated in hedonic manner, the potential visitor could increase their involvement with the advertisement, resulting in a higher intention of choice of the destination. It is believed that 
the more sustainability stimuli are grounded in hedonic aspects, the greater will be the involvement of the consumer and their intentions of choice. Thereby, the following hypothesis is presented: H3: A hedonic sustainability stimulus inserted in the communication of a tourist destination has greater positive impact in the behavioral intention when the consumer involvement towards the stimulus is more positive.

\subsection{Consumer ecological awareness}

Some studies show that despite the growing acknowledgment of the importance of adjusting consumption, there has not been yet a full comprehension on the consumers' behalf of the implications of their consumption acts on the environment (Dinato \& Madruga, 1998; Rettie, Burchell \& Barnham, 2014). On the other hand, there are several consumers who present elevated levels of ecological awareness and the greater the awareness, the greater their intentions to take care of nature (Roberts, 1996).

Although not many studies about behavioral aspects regarding tourism or related service were identified, it is observed that those who analyze consumers' attitudes indicate how they behave towards sustainability issues, especially environmental. Manaktola \& Jauhari (2007), for instance, explored consumers' attitudes and behavior regarding green practices in the hospitality sector in India. The authors demonstrated that consumers are more likely to consume products and services that develop environmental and sustainable actions, but are not willing to pay more for those services. Aiming to examine if the "green actions" practiced by hotels contribute to the consumers' satisfaction, Robinot \& Giannelloni (2010) conducted a qualitative study that helped create a list of characteristics that contribute to the general satisfaction with a hotel. The main results showed that the environmental attributes were evaluated as basic; which means they were seen as part of the utilitarian service offer and not as differentiating criteria. Okada \& Mais (2010) defend that individuals are more sensitive to sustainability issues and agree with the idea that they are willing to pay a higher value for "green" products and services. They concluded that positive frame (focusing on the advantages of green product) functions better for the consumers environmentally aware, as the negative frame (focusing on avoiding the disadvantages of the non-green product) functions better for the less aware.

Based on some analyzed studies, it is possible to consider that environmental concern of consumer as a tourist has direct positive impact in their behavioral intentions (Lee \& Holden, 1999; Robinito \& Giannelloni, 2010; Pagiaslis \& Krontalis, 2014) and the ecological lifestyle is positively associated to the behavioral intentions (Chen, 2014). Rettie, Burchell \& Barnham (2014) observed that consumers that are more likely to adopt pro-environmental behavior are those who consider that practice normal. Thereby, it is believed that their responses of behavioral actions would be based on a rational behavior structure, since they are considered normal. On the other hand, that would be a valid relation for those who present high ecological awareness; corroborating with Okada \& Mais (2010). Therefore, facing those considerations, it was formulated the following hypothesis, hitherto not tested empirically: H4: A hedonic sustainability stimulus inserted in the communication of a tourist destination has a greater positive impact in behavioral intention when consumer has low ecological awareness.

\subsection{Design, sample and scenarios}

The study design was factorial with emotion, involvement and ecological awareness, covariates moderating of the relationship between the type of sustainability stimulus and consumer intent, being manipulated between groups. The sample was non-probability, composed by graduation students (with habit of traveling on holidays or long weekends), with survey conducted in presence by the researchers on December 2014.

Bentivegna (2013) elaborated a scheme resuming the main characteristics to develop a communication. In the proposal, the author directs the factors that must be contemplated in the execution of advertisements, these being: a) factors related to the product; $b$ ) to the audience; $c$ ) to the brand; and d) to the content and appearance. Except for item ' $c$ ', these factors were contemplated in the stage of developing the material (poster) used to compose the scenario.

To Shavitt (1990) rational advertisement is more effective for rational products and emotional, for emotional products. Therefore, to obtain a most suitable effect of the impact of each type of message, it is necessary to work with products presenting equally strong characteristics. Even considering that tourism is naturally more emotional, it was aimed to verify if the types of tourism may be interpreted as rational or emotional, since the communication appeal is aiming sustainability, this being consisted of more rational aspects.

The analyzed contexts of tourism were adventure, cultural, ecological, gastronomical, nautical, religious and "sun and beach". The chosen proposal was made by Chang (2006). It consists in two items in which participants must indicate their level of agreement in a scale of 7 points, based on the phrases: "when I purchase sneakers, I consider whether the brand or style fits my image". In the sample conducted with 90 individuals, adventure tourism ( $\mathrm{Mh}=5,03$; d.p=1,69| $\mathrm{Mr}=$ $5,42 ; d . p=1,58 ; p=0,067)$, gastronomic ( $M h=4,97 ; d . p=1,96$ । $\mathrm{Mr}=5,42 ; d . p=1,70 ; \mathrm{p}=0,083)$ and religious $(\mathrm{Mh}=5,13$; d. $p=2,11 \mid \mathrm{Mr}=4,86 ; d \cdot p=2,17 ; \mathrm{p}=0,262$ ) presented equally strong rational and emotional characteristics, confirmed by the non-significant difference (Wilcoxon Test, $p<0,05$ ) between the averages of the questions (Chang, 2006).

Therefore, to elaborate the scenarios it was considered as context the adventure tourism represented by the city of Bonito, Pernambuco, Brazil. A group of six marketing specialists (doctorate students and doctor professors) elaborated and verified the texts with hedonic and rational arguments in a face validation process. A graphic designer prepared the poster picture and the specialists 
validated once more the finished piece, which they considered appropriate for experimentation by the end of the process.

\section{Measurement and Analysis of Reliability and Validity}

In order to measure behavioral intention, considering the tourism context, four variables were elaborated, inspired in the items of the behavioral intention scale proposed by Byron \& Zhang (2010). The Emotions were measured based on eight variables from Richins (1997). Roberts (1996) measured ecological awareness from the EC scale (Environmental Concern). The involvement was measured as from five items of the Personal Involvement Inventory (PII) scale of Zaichkowsky (1985) - (enchantment, excitement, happiness, anxiety and tranquility). A 10 points scale of the Likert type also collected the variables.

The reliability and validity of the scales were analyzed by means of an Alfa Cronbach coefficient and exploratory factorial analysis (EFA). For the Study 1 , the results were: intention $\alpha=0,878$ (var=73,19\% | KMO=0,829, Bartlett $=301,625$ with 6 g.l., p<0,000); emotion $\alpha=0,747$ (var=68,48\% | KMO=0,776, Bartlett $=215,114$ with 10 g.l., $p<0,000$ ); involvement $\alpha=0,869$ (var $=66,06 \%$ | KMO $=0,805$, Bartlett $=260,283$ with 10 g.l., $p<0,000$ ); ecological awareness $\alpha=0,689$ (var $=63,61 \% \quad$ । $\mathrm{KMO}=0,619$, Bartlett $=321,446$ with 10 g.l., $\mathrm{p}<0,000$ ).

Following the same analysis strategy, in Study 2, the results were: intention $\alpha=0,925$ (var $=81,63 \% \quad \mid \mathrm{KMO}=0,843$, Bartlett $=332,411$ with 6 g.l., $p<0,000$ ); emotion $\alpha=0,746$ (var $=64,76 \%$ | KMO=0,746, Bartlett $=194,991$ with 6 g.l., $p<0,000$ ); involvement $\alpha=0,869$ (var $=66,06 \%$ | KMO $=0,805$, Bartlett $=260,283$ with 10 g.l., $p<0,000$ ); ecological awareness $\alpha=0,689$ (var=63,61\% | KMO=0,619, Bartlett=321,446 with 10 g.l., $p<0,000)$. As observed, results presented themselves as satisfactory to both studies.

\section{Study 1}

The checking of rational and hedonic sustainability stimuli in adventure tourism context was conducted by evaluating the level of consistency between the answers from the participants who evaluated the rational $(75,2 \%)$ and hedonic $(78,8 \%)$ posters in each group. For 30 seconds, each group saw only a manipulated condition, and from the authorization of the researcher, responded to the questionnaire. Even setting a starting time, the poster remained available for observation.

\section{Sample Profile}

146 valid questionnaires were obtained, where $47,3 \%$ referred to the group receiving the rational stimulus and $52,7 \%$ the hedonic. Considering both groups, $54,8 \%$ were men and $45,2 \%$ women, and the majority $(78,1 \%)$ reside in the Metropolitan Region of Recife, Brazil. They are young (24 years old | d.p.=5, 26) single $(92,5 \%)$ who attend higher education. They have monthly family income on an average of $R \$ 7.167,96$ with d.p. $=R \$ 6.102,27$, varying from $R \$ 600,00$ to $R \$ 40.000,00$. It was found that $63,7 \%$ are in the habit of making leisure trips and consider the internet as the main way to find information on tourist destinations $(74,0 \%)$. It was also seen that $81,5 \%$ of the participants are willing to pay additional fees to visit a tourist destination that adopts sustainability practices, of which $23,3 \%$ would pay up to $5 \%$ more, $39,0 \%$ up to $10 \%, 14,4 \%$ up to $15 \%, 7,5 \%$ up to $20 \%$ and $1,4 \%$ more than $20 \%$ compared to normal value.

\section{Direct Effect Analysis}

Variance analysis (ANOVA) tested the hypothesis. The $\mathrm{H} 1$ indicates that hedonic sustainability stimulus inserted in the communication of a tourist destination creates more positive behavior intention on the tourist consumer. Despite the hedonic stimulus has generated higher averages, (MHedonic Stim. $=5,22$ vs. MRationalStim. $=4,55$ ), according to the ANOVA exam, its effect over the intention to visit a destination was not significant $(F(1,145)=2,502 ; p=0,106)$. Based on those results, $\mathrm{H} 1$ was not sustained.

\section{Analysis of the Impact of Moderating Variables}

It was aimed to analyze separately the impact of emotion, involvement and environmental awareness in the relationship between the rational and hedonic sustainability stimuli and intention to visit a destination. Initially, $\mathrm{H} 2$ indicates that a hedonic sustainability stimulus inserted in the communication of a tourist destination has a greater positive impact in the behavioral intention when the emotional response from the consumer towards the stimulus is more positive. According to ANOVA examinations, both sustainability stimulus $(F(1,142)=$ $3,912 ; p=0.05)$ and emotion $(F(1,142)=33,68 ; p=0,00)$ presented significant effects in the model. The group that had seen the hedonic sustainability poster and had had greater emotional response (MEmotionHIgh =6,06 | MEmotionLow =3,67), presented a greater intention to visit the destination. The group that had received the rational sustainability stimulus from the poster (MEmotionHigh = 5,24| MEmotionLow $=2,85$ ) presented the same behavior, but with lower averages. The moderating effect of emotion in the relation between sustainability stimulus and intention was not significant $(F(1,146)=0,00 ; p=0,99)$ (Graphic 1). However, it was observed that the hedonic sustainability stimulus created greater intention when the emotional response was higher, sustaining $\mathrm{H} 2$.

\section{Graphic 1 - Effect of emotion in the relation of sustainability stimulus and intention}

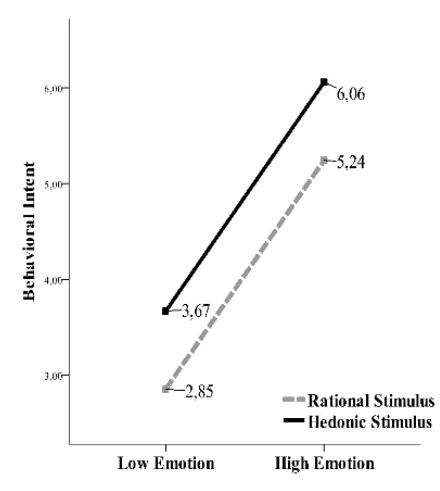


$\mathrm{H} 3$ indicates that a hedonic sustainability stimulus inserted in the communication of a tourist destination has a greater positive impact in behavioral intention when the involvement of the customer towards that type of stimulus is greater. The ANOVA results indicate that the sustainability stimulus ( $F$ $(1,142)=2,03 ; p=0,16)$ did not present significant effect in the model, unlike involvement $(F(1,142)=49,44 ; p=0,00)$.

Data indicates that when the sustainability stimulus was hedonic, the consumers with high involvement (MInv. High $=6,36$ । MInv.Low $=3,43$ ) had greater intention to visit the presented destination, having the same behavior to those who saw the poster with the ration stimulus (MInv. High = 5,53 | MInv.Low = $3,21)$. The moderating effect in the involvement at the relation between sustainability stimulus and intention, was not significant $(F(1,142)=0,67 ; p=0,42)$ (Graphic 2). However, it was found that the consumers had greater intention to visit the tourist destination when their involvement with the poster presenting the hedonic sustainability appeal was greater, sustaining $\mathrm{H} 3$.

\section{Graphic 2 - Effect of the involvement in the relation of} sustainability stimulus and intention

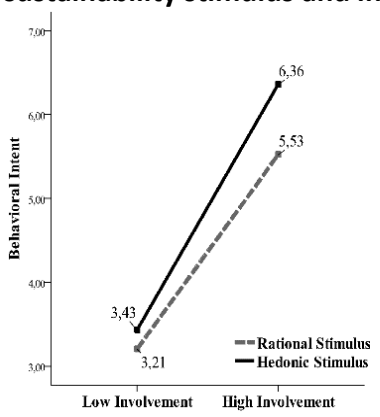

In $\mathrm{H} 4$ it was verified that ecological awareness does not moderate the relation between sustainability stimulus and intention ( $F$ $(1,142)=0,009 ; p=0,925)$. In order to test $\mathrm{H} 4$ it was selected only part of the sample of consumers with low ecological awareness (16\%). To test hypothesis 4, those who evaluated the poster with the hedonic stimulus presented higher averages of intention to visit compared to those who had seen the poster with rational appeal (MStim.hedonic $=4,4$ vs. MStim.rational $=3,7$ ). Nonetheless, according to the ANOVA results, the difference was not significant $(F(1,22)=0,389 ; p=0,540)$ (Graphic 3); unable to sustain $\mathrm{H} 4$. In this study, the hedonic sustainability stimulus inserted in the communication of a tourist destination did not have a greater positive impact in the behavioral intention of consumers with low ecological awareness.

Graphic 3 - Effect of the awareness in the relation between sustainability stimulus and intention

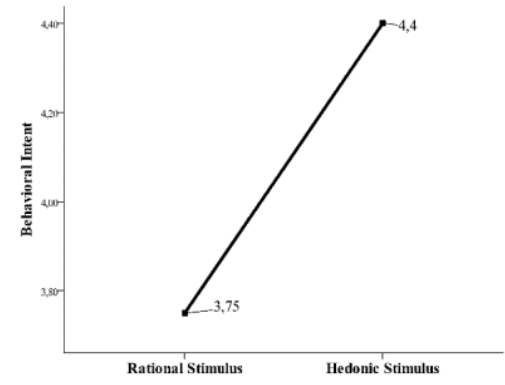

\section{Study 2}

The same scenario and gathering procedures adopted in the first study were used in the second. However, in complementary manner, textual scenarios were added that led the participants to imagine themselves in a situation of choice of a tourist destination for a holiday travel in a most impactful way. In the stimuli checking were obtained $73,8 \%$ of consistency among the answers from the participants who evaluated the rational poster and $77,5 \%$ from the emotional; results also considered appropriate.

\section{Sample Profile}

105 valid questionnaires were obtained, of which $48,6 \%$ referred to the group that received rational stimulus and $51,4 \%$ to the hedonic. Considering both groups, $45,7 \%$ were men and $53,3 \%$ were women, and the majority $(75,2 \%)$ reside in the Metropolitan Region of Recife, Brazil. They are young adults (28 years old | d.p. $=8,19)$ single $(72,5 \%)$ who attend higher education and postgraduate degrees. They have monthly family income on an average of $R \$ 8.207,21$ with $d . p=R \$ 6.212,70$, varying from $R \$ 1100,00$ to $R \$ 40.000,00$. It was found that $61,0 \%$ have the habit of making leisure trips and consider the internet as the main way to find touristic information about tourist destinations $(78,1 \%)$. It was also seen that $82 \%$ of the participants are willing to pay additional fees to visit a tourist destination that adopts sustainability practices, of which $25,7 \%$ would pay up to $5 \%$ more, $38,1 \%$ up to $10 \%, 12,4 \%$ up to $15 \%$, $7,6 \%$ up to $20 \%$ and $1,9 \%$ more than $20 \%$ compared to normal value. The average age in this sample was higher than on the previous one.

\section{Direct Effect Analysis}

The hedonic sustainability stimulus inserted in the tourism poster created greater averages of behavioral intention to visit (MStim. hedonic $=5,22$ vs. MStim. rational $=4,55$ ), which makes the effect of that appeal significant, according to the ANOVA exam $(F(1,104)=13,02 ; p=0,000)$. Based on these results, it was verified that the hedonic sustainability stimulus inserted in the communication of the analyzed tourist destination created greater positive behavioral intention by the consumer. Therefore, $\mathrm{H} 1$ was sustained.

\section{Impact Analysis of the Moderating Variables}

Following the same logic of analysis from the first study, $\mathrm{H} 2$ seeks to identify the impact of emotion in the relation between hedonic sustainability stimulus and intention. According to the ANOVA exam, both sustainability stimulus $(F(1,101)=19$, 52; $p=0,000)$ and emotion $(F(1,101)=21,74 ; p=0,000)$ presented significant effects in the model. The group that saw the hedonic sustainability poster had greater level of emotion (MEmotionHigh = 6,06 | MEmotionLow = 3,67). The group that saw the hedonic sustainability poster and had high emotion level (MEmotionHigh = 7,41 | MEmotionLow = 4,8), presented greater intention to visit the destination. In the same manner, to the group that received the rational sustainability stimulus in 
the communication (MEmotionHigh = 4,92 | MEmotionLow = $3,0)$, but with much lower averages. The moderating effect of emotion in the relation between the sustainability stimulus and intention, was not significant $(F(1,101)=0,51 ; p=0,48)$ (Graphic 4). It was observed, however, that the hedonic sustainability stimulus created greater intention when the emotional response was greater, sustaining $\mathrm{H} 2$.

\section{Graphic 4 - Effect of emotion in the relation between sustainability stimulus and intention}

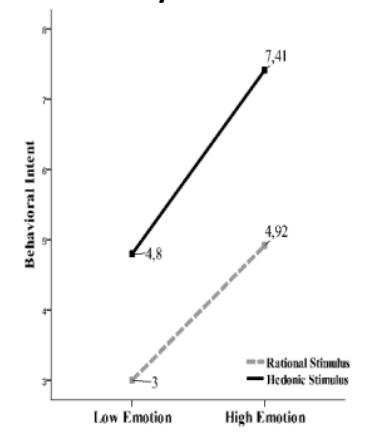

The ANOVA results for $\mathrm{H} 3$ indicate that the sustainability stimulus $(F(1,101)=12,09 ; p=0,001)$ and involvement $(F(1,101)$ $=19,43 ; p=0,000)$ present significant effects in the model. When the sustainability stimulus was hedonic, consumers with high involvement (MInv. High = 7,46 | MInv.Low = 5,04) had greater intention to visit a presented destination, having the same behavior as those that saw the poster with the rational stimulus (MInv.High = 5,47| MInv.Low = 3,75).

The moderating effect of involvement in the relation between sustainability stimulus and intention was also not significant ( $F$ $(1,101)=0,56 ; p=0,45)$ (Graphic 5). Even with similar behavior between the groups, it was found that the consumer had greater intention to visit the tourist destination when their involvement with the poster that presented the hedonic sustainability appeal was greater, sustaining H3.

Graphic 5 - Effect of the involvement in the relation between sustainability stimulus and intention

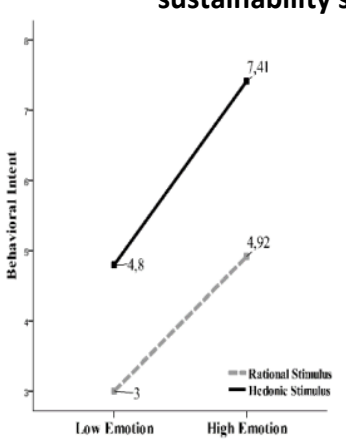

In $\mathrm{H} 4$, it was verified that ecological awareness does not moderate the relation between sustainability stimulus and intention $(F(1,142)=0,009 ; p=0,925)$. In order to test $\mathrm{H} 4$ it was selected only part of sample of consumers with low ecological awareness (21\%). Unlike the first study, the ANOVA result to this hypothesis test was significant $(F(1,21)=9,24 ; p=0,006)$ (Graphic 6), enabling $\mathrm{H} 4$ to be sustained. Thereby, the consumers with low ecological awareness that evaluated the poster with the hedonic sustainability stimulus presented greater intention to visit a destination when compared to the averages of those who saw the poster with rational sustainability appeal (MStim. hedonic $=5,4$ vs. MStim.rational = 2,9).

Graphic 6 - Effect of ecological awareness in the relation between sustainability stimulus and intention

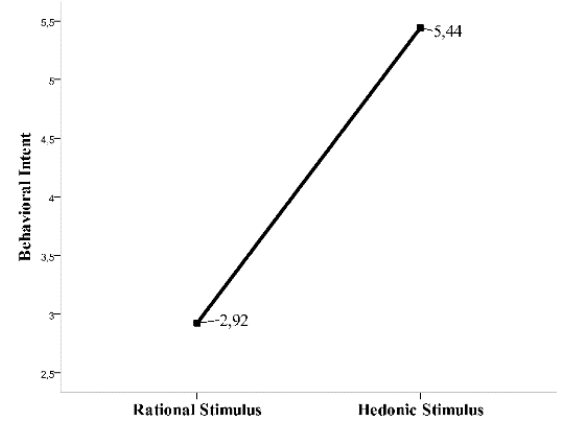

\section{Conclusions}

Since the end of last century, people are going through a process of change in their behavior towards consumption of goods and services, especially those who are younger (Lee \& Holden, 1999; Okada \& Mais, 2010; Robinot \& Giannelloni, 2010). To tourism activity, that information points to a possible change on people's behavior, and that transformation is crucial so that the further generation can also enjoy the natural and structural beauties that are explored by tourist activity.

It was verified that hedonic sustainability stimulus produces a more positive effect over emotion, involvement and, subsequently, over behavioral intention to visit a destination by the consumer. Therefore, despite not presenting significant interaction, emotional responses, as well as the involvement impacted positively the relation between rational and hedonic sustainability stimulus and behavioral intention, something yet not evaluated scientifically. In this sense, the study contributes to literature by revealing that although the constructs emotion, involvement, and ecological awareness are not strong moderators in the relation between rational or hedonic sustainability stimulus and behavioral intention, are aspects that when positively activated, especially from the hedonic arguments of sustainability, create greater intention to visit the place on the consumers' behalf.

It was also possible to find that people with low ecological awareness tend to have more positive responses of intention when facing hedonic sustainability stimuli. In this way, the study also contributes theoretically demonstrating that those consumers with high awareness are more sensitive to the rational sustainability stimulus, whilst those with low awareness, to the more hedonic appeals. This result indicates a new perspective of analysis and may help in a better conduction of tourism communication strategies, when the goal is to involve the less aware consumers with the practices of preservation of the destination during the visitation. 
Considering the manner in which the research was conducted, as well as the results achieved, it is believed that textual arguments may actually be more relevant to supply the possible contextual incompatibility raised between tourism and sustainability in tourism communication; since these can be interpreted as more emotional and rational, respectively, when its practical essences are considered. Thereby, the study advances in marketing literature, also demonstrating that facing contexts in which emotional and rational elements are characteristic, such as sustainable tourism, it becomes necessary to work with textual elements in communication, in a way that fills this gap; something not considered in the studies from Hartmann, Ibáñez \& Sainz (2005) and Matthes, Wonneberger \& Schmuck (2014), for instance.

It is emphasized as researches limitations, the difficulty to control the extraneous variables, the equivalence of the samples, as well as the characteristics of the participants, mostly young people. There are certainly limitations regarding the adaptations related to the method here used, as the execution of the experiments out of the well-built laboratories for better control of the materials used in the process. However, it is believed that the theoretical foundation conducted, the care in the procedures for the development of scenarios and the manner in which the gathering process was held allow the results to be academically valid and stimulate the execution of studies with use of other methodological procedures, as well as scenarios with other touristic contexts and different types of sustainability appeals.

\section{References}

Aaker, D. A. (1996) Criando e administrando marcas de sucesso. São Paulo: Futura.

Andrades-Caldito, L., Sánchez-Rivero, M. \& Pulido-Fernández, J. I. (2014) Tourism destination competitiveness from a demand point of view: an empirical analysis for Andalusia. Tourism Analysis, 19(4), 425-440.

Andrews, J., Srinivas, D. \& Akhter, S. H. (1990) A framework for conceptualizing and measuring the involvement construct in advertising research. Journal of Advertising, 19(4), 27-40.

Ajzen, I., Albarracín, D. \& Hornik, R. (2007) Prediction and change of health behavior: Applying the reasoned action approach. Mahwah, NJ: Lawrence Erlbaum Associates.

Allen, M. W. (2000) The attribute-mediation and Product Meaning approaches to the influences of human values on consumer choices. Advances in Psychology Research, 1. 31-76.

Bentivegna, R. J. (2013) Efetividade da propaganda racional $e$ emocional de marcas: Impacto de subculturas regionais. São Paulo: FGV, 2013. 227 f. Tese. Programa de Pós-graduação em Administração, Fundação Getúlio Vargas, São Paulo.

Brunner-Sperdin, A. \& Peters, M. (2009) What influences guests' emotions? The case of high-quality hotels. International Journal of Tourism Research, 11(2), 171-183.

Byon, K. K. \& Zhang, J. J. (2010) Development of a scale measuring destination image. Marketing Intelligence \& Planning, 28(4), 508-532.

Chang, C. (2006) Cultural masculinity/femininity influences on advertising appeals. Journal of Advertising Research, 46(3), 315-323.

Chen, K. K. (2014) Assessing the effects of customer innovativeness, environmental value and ecological lifestyles on residential solar power systems install intention. Energy Policy, 67(apr), 951-961.
Clarke, K. \& Belk, R. (1978) The effects of product involvement and task definition on anticipated consumer effort. Advances in Consumer Research, 5, 313-318.

Dinato, M. R. \& Madruga, K. (1998) Technological innovation and performance of the green products in the brazilian market: a multisectorial analysis. In: 7th International Conference on Management of Technology, 1998, Flórida. Proceedings.

Edell, J. A. \& Burke, M. C. (1987) The power of feelings in understanding advertising effects. Journal of Consumer Research, 14(3), 421-33.

Fishbein, M. \& Ajzen, I. Belief, Attitude, Intention, and Behavior: An Introduction to Theory and Research. Reading, MA: Addison-Wesley.

Gross, M. \& Brown, G. (2008) An empirical structural model of tourists and places: progressing involvement and place attachment into tourism. Tourism Management, 29(1), 1141-1151.

Gilmore, J. H. \& Pine II, B. J. (2002) Customer experience places: the new offering frontier. Strategy \& Leadership, 30(4), 4-11.

Hartmann, P., Ibáñez, V. A. \& Sainz, F. J. F. (2005) Green branding effects on attitude: Functional versus emotional positioning strategies. Marketing Intelligence \& Planning, 23(1), 9-29.

Hartmann, P. \& Apaolaza-Ibáñez, V. (2009) Green advertising revisited: Conditioning virtual nature experiences. International Journal of Advertising, 28(4), 715-739.

Hirschman, E. \& Holbrook, M. B. (1982) Hedonic consumption: emerging concepts, methods and propositions. Journal of Marketing, 46(3), 92-101.

Lastovicka, J. L. \& Gardner, D. M. (1978) Low involvement versus high involvement cognitive structures, in Kent Hunt, Ann Abor (eds.) Advances in Consumer Research, 5 (pp. 87-92), MI: Association for Consumer Research.

Laurent, G. \& Kapferer, J-N. (1985) Measuring consumer involvement profiles. Journal of Marketing Research, 22(1), 41-53.

Lee, J. A. \& Holden, S. J. S. (1999) Understanding determinants of environmentally conscious behavior. Psychology \& Marketing, 16(5), 373-392.

Lwin, M., Phau, I., Huang, Yn-An \& Lim, A. (2014) Examining the moderating role of rational-versus emotional-focused websites. Journal of Vacation Marketing, 20(2), 95-109.

Malone, S., McCabe, S. \& Smith, A. P. (2014) The role of hedonism in ethical tourism. Annals of Tourism Research, 44(jan), 241-254.

Manaktola, K. \& Jauhari, V. (2007) Exploring consumer attitude and behavior towards green practices in the lodging industry in India. International Journal of Contemporary Hospitality Management. 19(5), 364-377.

Matthes, J., Wonneberger, A. \& Schmuck, D. (2014) Consumers' green involvement and the persuasive effects of emotional versus functional ads. Journal of Business Research, 67(9), 1885-1893.

Michaelidou, N. \& Dibb, C. S. (2006) Product involvement: an application in Clothing. Journal of Consumer Behaviour, 5(5), 442-453.

Miller, D., Merrilees, B. \& Coghlan, A. (2015) Sustainable urban tourism: understanding and developing visitor pro-environmental behaviors. Journal of Sustainable Tourism, 23(1), 26-46.

Mittal, B. (1989) Measuring purchase-decision involvement. Psychology and Marketing, 6(2), 147-162.

Mittal, B. \& Lee, M. S. (1989) A causal model of consumer involvement. Journal of Economic Psychology, 10(3), 363-389.

Mossberg, L. (2008) Extraordinary Experiences through Storytelling. Scandinavian Journal of Hospitality and Tourism, 8(3), 195-210.

Okada, E. M. \& Mais, E. L. (2010) Framing the "green" alternative for environmentally conscious consumers. Sustainability Accounting, Management and Policy Journal, 1(2), 222-234.

Ottman, J. (2012). As novas regras do marketing verde - estratégias, ferramentas e inspiração para o branding sustentável. São Paulo: M. Books. 
Pagiaslis, A. P. \& Krontalis, A. K. Green consumption behavior antecedents: environmental concern, knowledge, and beliefs. Psychology \& Marketing, 31(5), 335-348.

Petty, R. E. \& Cacioppo, J. T. (1990) Involvement and persuasion: tradition versus integration. Psychological Bulletin, 107(3), 367-374.

Rettie, R., Burchell, K. \& Barnham, C. (2014) Social normalization: Using marketing to make green normal. Journal of Consumer Behaviour, 13(1), 9-17.

Richins, M. L. (1997) Measuring emotions in consumption experience. Journal of Consumer Research, 24(2), 127-146.

Roberts, J A. (1996) Green consumers in the 1990s: profile and implications for advertising. Journal of Business Research, 36(3), 217231.

Robinot, E \& Giannelloni, J. L. (2010) Do hotels' "green" attributes contribute to customer satisfaction? The Journal of Services Marketing, 24(2), 157-169.

Samuelsen, B. M. \& Olsen, L. E. Promising attributes and experiences: attitudinal responses to functional versus experiential ad claims and the moderating role of involvement. Journal of Advertising, 39(2), 65-77.

Schmidt, A. \& Donsbach, W. (2012) „Grüne“ Werbung als Instrument für „schwarze“ Zahlen. Publizistik, 57(1), 75-93.

Shavitt, S. (1990) The Role of Attitude Objects in Attitude Functions. Journal of Experimental Social Psychology, 26(2), 124-148.

Searles, K. (2010) Feeling good and doing good for the environment: The use of emotional appeals in pro-environmental public service announcements. Applied Environmental Education and Communication, 9(3), 173-184.

Sigala, M. (2014) Customer involvement in sustainable supply chain management a research framework and implications in tourism. Cornell Hospitality Quartely, 55(1), 76-88.

Walker, K. \& Moscardo, G. (2014) Encouraging sustainability beyond the tourist experience: ecotourism, interpretation and values. Journal of Sustainable Tourism, 22(7), 1175-1196.

Xu, J. B. (2010) Perceptions of tourism products. Tourism Management, 31(5), 607-10.

Zaichkowsky, J. L. (1985) Measuring the involvement construct. Journal of Consumer Research, 12(dec), 341-352.

Received: 17.02.2017

Revisions required: 23. 08.2017

Accepted: 15.02.2018 